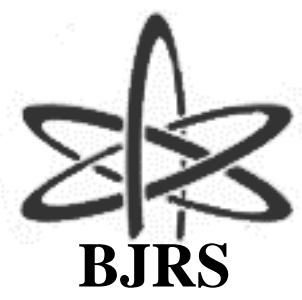

\author{
BRAZILIAN JOURNAL \\ $\mathrm{OF}$ \\ RADIATION SCIENCES \\ 08-03A (2020) 01-18
}

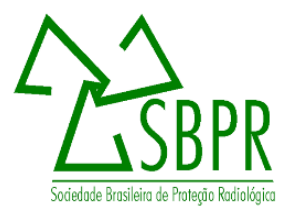

\title{
Advanced Heavy Water Reactor: A New Step Toward Sustainability
}

\author{
Ricardo Bastos Smith, Mahima Sachdeva, Indranil Bisuri, Roberto Vicente \\ Nuclear \& Energy Research Institute (IPEN/CNEN-SP) \\ rbsmith@ipen.br
}

\begin{abstract}
One of the great advances in the current evolution of nuclear power reactors is occurring in India, with the Advanced Heavy Water Reactor (AHWR). It is a reactor that uses thorium as part of its fuel, which in its two fueling cycle options, in conjunction with plutonium or low enriched uranium, produces energy at the commercial level, generating less actinides of long half-life and inert thorium oxide, which leads to an optimization in the proportion of energy produced versus the production of burnt fuels of the order of up to $50 \%$. The objective of this work is to present the most recent research and projects in progress in India, and how the expected results should be in compliance with the current sustainability models and programs, especially the "Green Chemistry", a program developed since the 1990s in the United States and England, which defines sustainable choices in its twelve principles and that can also be mostly related to the nuclear field. Nevertheless, in Brazil, for more than $\mathbf{4 0}$ years there has been the discontinuation of research for a thorium-fueled reactor, and so far there has been no prospect of future projects. The AHWR is an important example as an alternative way of producing energy in Brazil, as the country has the second largest reserve of thorium on the planet.
\end{abstract}

Keywords: advanced heavy water reactor, thorium-based nuclear power, India nuclear program, Brazilian thorium group, green chemistry. 


\section{INTRODUCTION}

With the growing need for electricity for human beings, as well as the progressive depletion of fossil fuel reserves and concerns related to global warming, nuclear power is increasingly becoming an important option to contribute substantially in attending the global energy needs. The Human Development Report's per capita electricity consumption data indicates that the world may need 3,000 to 4,000 nuclear reactors to meet this energy need [1].

In addition, the concern about human health and the environment through the reduction of pollution and waste production has increased since the mid-twentieth century, when the long-term negative effects of human activities since the Industrial Revolution became increasingly present. It was clear that the search for cleaner production means, as well as the treatment of waste produced in the most diverse areas, would become a matter not only of well-being but even of survival.

Associations and entities have progressively emerged around the world with the specific objective of controlling and revising the procedures used in laboratories, industries and energy production facilities, in an attempt to minimize or even reverse the environmental damage. In the 1980s and 1990s several environment-friendly terms were coined, including Green Chemistry, which later became the subject of a set of 12 principles for elimination or reduction of hazardous substances applied accross the life cycle of any chemical product, including its design, manufacture, use, and ultimate disposal [2]. These principles can be mostly applied also to the nuclear area, as presented in the following pages.

After World War II, nuclear power for peaceful purposes became a fruitful field of research for developing countries, such as India and Brazil. Beginning in 1954 with the construction of the Bhabha Atomic Research Centre (BARC) [3], India has developed a nuclear program known as the "Thorium Utilisation Programme for Sustainable Energy", envisaging the definitive transition to a fuel cycle based on thorium, due to its abundant sources and the shortage of uranium in the country.

India's nuclear programme is divided into three stages, in which the waste produced in the nuclear power reactor of the first stage becomes the fuel for the reactor of the next stage, and so on. The Advanced Heavy Water Reactor (AHWR) is the key component of the third stage. This new type of reactor, under construction, when in operation will also contribute to the reduction of 
radioactive waste generation, as it will use a fuel cycle with a smaller production of actinides. In addition, as the thorium oxide has a chemically inert nature, its deposition as a burnt fuel is less harmful [4].

Therefore, this paper presents a brief history about the evolution of the concept of sustainable development and some of the main organizations involved. Afterwards, the main characteristics of the Advanced Heavy Water Reactor will be presented, as well as an analysis on how the Indian reactor seems consistent with these trends of increased safety and sustainability assurance, including the Green Chemistry principles. Finally, there was a moment in time when Brazil and India developed similar lines of research, in the development of a nuclear power reactor powered by thorium. However, Brazil followed a different path a few years later, and the research with thorium was discontinued. Such a Brazilian undertaking should not fall into oblivion.

\section{SUSTAINABLE DEVELOPMENT: BACKGROUND}

Sustainable development has been defined in many ways, but the most frequently quoted definition comes from the Brundtland Report, Our Common Future: "Sustainable development is the one that meets the needs of the present without compromising the ability of future generations to meet their own needs" [5]. It is the economic, social, cultural and scientific development of societies, ensuring more health, comfort and knowledge, but without depleting the planet's natural resources. To this end, every form of relationship between man and nature must occur with the least possible damage to the environment. Policies, systems of trade, production, transformation and service, industry, tourism, agriculture, basic services, mining, and others must exist to preserve biodiversity and the human being, that is, to protect the life of the planet [6].

The post-World War II economic expansion, also known as the postwar economic boom or Golden Age of capitalism, was a period of economic prosperity in the mid-twentieth century which provoked the acceleration of environmental change processes, as a result of seemingly unlimited economic growth in terms of resource availability [7].

The continuing and intense deterioration of the environmental situation, initially marked by industrial pollution, set precedents for the struggle in taking into account the environmental issues. 
Therefore, there is nowadays a growing awareness and concern at all levels of society and practically every nation regarding the environmental problems.

In order to meet the social demands motivated by environmental accidents, increased pollution of the soil, water and air, and changes in the socio-political context worldwide, a series of actions were taken to create alternatives for the improvement of the environmental situation, which at that time already demonstrated its gravity.

Historically, the starting point of the environmental issue was the Intergovernmental Conference of Experts on the Scientific Basis for Rational Use and Conservation of the Resources of the Biosphere, or the Biosphere Conference, organized by UNESCO in 1968 in Paris [8]. This conference focused on the scientific aspects of biosphere conservation, as well as research in the field of Ecology. One of the most important warnings at the time was the report commissioned by the Club of Rome, an international association of intellectuals, scientists, and entrepreneurs, entitled “The Limits to Growth", published in 1972, also known as the Meadows Report, which was commissioned to technicians and scientists at the Massachusetts Institute of Technology (MIT) in the United States [9]. The published results disclosed the warnings and presented two possibilities: the occurrence of changes in the economic growth standards, or an ecological collapse in the next hundred years.

The document nurtured the debate at the Stockholm Conference, also held in that same year, where an understanding about the relationship between environment and development was established, and the concept of a new type of development emerged: the Ecodevelopment - a proposition for new modalities of development, which promotes the knowledge produced by local populations for the management of their environment, as opposed to the homogenization of the models adopted until then.

Sequentially, the Stockholm Conference - United Nations Conference on the Human Environment took place, in which political, social and economic problems in the global environment were discussed, in an intergovernmental forum. The United Nations Environment Program (UNEP) was then created, during some of these discussions. The concept of Ecodevelopment was gradually being replaced by the concept of Sustainable Development, which use comes from a document prepared in 1980 by the International Union for Conservation of Nature (IUCN) [10]. 
In the nuclear field, until 1982, some of the radioactive waste produced by the 13 most evolved countries in the area used to be placed in drums and thrown into the deepest places in the ocean. According to an inventory organised by the International Atomic Energy Agency, approximately $85.0 \times 10^{15} \mathrm{~Bq}$ of radioactive waste were discharged into the ocean [11]. The emission of radioactive gases and aerosols because of the atomic tests in the atmosphere had already been halted in 1963 by the Partial Nuclear Test Ban Treaty; an order of magnitude greater than $1.0 \times 10^{21} \mathrm{~Bq}$ is estimated of radioisotopes that were dispersed in the air by the 520 nuclear tests on Earth's surface, eight of them under water [12].

Ten years after the Stockholm meeting in 1982, an assessment of the period was performed at a meeting sponsored by UNEP, in Nairobi, which suggested the formation of the World Conference on Environment and Development - UNCED, set up by the United Nations in 1983 to analyze environmental and developmental problems. This commission published in 1987 its report, which became known as the Brundtland Report, the book entitled Our Common Future [5]. Afterwards, the environmental issue received a further impetus and the concept of sustainable development started being used instead of the ecodevelopment term, and formed the basis for the discussion and reorientation of development policies and their direct relationship with environmental issues.

In the mid 1980s, a shift in paradigm occurred in the Organisation for Economic Co-operation and Development (OECD) countries. During the 1985 meeting of the Environment Ministers of the OECD countries, the focus was on Economic Development and the Environment, Pollution Prevention and Control, and Environmental Information and National Reviews. Between this meeting and 1990 several decisions and Recommendations were formulated, which also provided the foundation for the Green Chemistry basics.

Internationally, the idea of command and control policy (often referred to as end-of-pipeline control) shifted towards an approach of pollution prevention [13]. The Pollution Prevention Act of 1990 in the United States marked a regulatory policy change from pollution control to pollution prevention as the most effective strategy for these environmental issues.

Based on the recommendations of the Brundtland Report, another conference was summoned by the United Nations General Assembly and held in Rio de Janeiro in 1992: the United Nations Conference on Environment and Development (UNCED), or ECO-92. This conference, also entitled Rio-92, was an important milestone for consideration on the environmental issue and its 
relationship with development. The debates centred on action strategies that could be adopted by all countries toward sustainable development, as well as conventions on climate change and biological diversity. Important documents were elaborated at Rio-92, such as the United Nations Agenda 21, which was a 40-chapter global action program adopted by 182 governments; and others, which also led to the Kyoto Protocol in 1997 [14].

The Agenda 21 and the Rio Declaration set essential policies for achieving a sustainable development model that meets the needs of the poor and recognizes the limits of development, in order to meet the global needs.

In 1997, the Rio +5 event was also held in Rio de Janeiro, discussing the actions and the proposals taken in ECO-92 that were not yet implemented. And in 2002, the United Nations organised the "World Summit on Sustainable Development", when representatives from different countries met in Johannesburg, South Africa, seeking to advance the discussions that began ten years earlier, and to outline the guidelines for sustainable development. This meeting was nicknamed as Rio +10 [15]. The same occurred ten years later, at Rio +20 .

In parallel to the Davos World Economic Forum in Switzerland, in 2001 the first World Social Forum (WSF) was held in the city of Porto Alegre, Brazil. A charter of social principles was drawn up after the first event, based on the participants' expectations and the meeting outcomes. With annual conferences and international participations, the WSF started being organised in other countries [16].

In September 2015, at the United Nations Summit, the 17 Sustainable Development Goals (SDGs) of the 2030 Agenda for Sustainable Development were defined, which officially came into force on 1 January 2016. Over the next fifteen years, with these new Goals that universally apply to all, countries should mobilize efforts to end all forms of poverty, fight inequalities and tackle climate change, while ensuring that no one is left behind [17].

\subsection{Green Chemistry}

As explained in the previous section, in the 1980s pollution prevention instead of end-ofpipeline control had to become the option of first choice. In that decade and in the 1990s, several environmentally conscious terms entered the chemical arena, such as: clean chemistry, 
environmental chemistry, green chemistry, benign chemistry and sustainable chemistry. The set of concepts now recognized as green chemistry coalesced in the mid- to late-1990s, along with broader adoption of the term.

In the United States, the Environmental Protection Agency (EPA) played a significant early role in fostering green chemistry through its pollution prevention programs, funding, and professional coordination. At the same time in the United Kingdom, researchers at the University of York contributed to the establishment of the Green Chemistry Network within the Royal Society of Chemistry, and the launching of the Green Chemistry journal [13].

In 1998, Paul Anastas, a US EPA representative, and John C. Warner (then of Polaroid Corporation) published the first handbook on green chemistry [18], defining it as the design of chemical products and processes that reduce or eliminate the use or generation of hazardous substances [2]. The breadth of the concept of such chemistry is demonstrated in twelve principles, as follows:

1. Prevent waste;

2. Maximize atom economy;

3. Design less hazardous chemical syntheses;

4. Design safer chemicals and products;

5. Use safer solvents and reaction conditions;

6. Increase energy efficiency;

7. Use renewable feedstocks;

8. Avoid chemical derivatives;

9. Use catalysts, not stoichiometric reagents;

10. Design chemicals and products to degrade after use;

11. Analyze in real time to prevent pollution;

12. Minimize the potential for accidents [2].

The Green Chemistry is regularly being applied nowadays in conjunction with the nuclear area, such as emerging separation techniques for nuclear fuel reprocessing and radioactive waste 
treatment $[19,20]$, as well as a practical example performed by Fuel America AREVA NP Inc. and the University of Idaho, in the extraction and purifying of enriched uranium from waste ash [21].

As presented by Lahiri, Choudhury and Sen [22], the development of new radiochemical methods is now dictated by the green chemistry mandates, especially in terms of choosing solvents and reagents. The practice of green chemistry has become an inevitable requisite in every facet of chemical process [23].

\section{INDIA'S NUCLEAR PROGRAM AND THE ADVANCED HEAVY WATER REACTOR}

The nuclear power program of India is divided into three stages: the first stage is to build the Pressurized Heavy Water Reactor (PHWR) using natural $\mathrm{UO}_{2}$ as fuel matrix, and heavy water as moderator and coolant. The isotopic concentration of natural $U$ is $0.7 \%$ fissile ${ }^{235} \mathrm{U}$ and the rest is ${ }^{238} \mathrm{U}$. The first two plants were of boiling water reactors based on imported technology. Subsequent plants are of PHWR type through indigenous research and development efforts. India has accomplished complete self-reliance in this technology, and this stage of the program is in the industrial domain [24].

The future plans of stage one include setting up the VVER (Water-Water Power Reactor) type plants based on Russian Technology, which is under progress to augment power generation. MOX fuel (Mixed oxide) is being developed and introduced at Tarapur to conserve fuel and to develop new fuel technology.

The nuclear fuel cycle can be open, if the spent fuel is not reprocessed and it alludes to the disposal of the entire fuel after being subjected to proper packaging. This results in huge underutilization of the potential energy of uranium (around $2 \%$ is exploited). In the closed cycle, on the other hand, the spent fuel is reprocessed and partly used, and it also refers to the chemical separation of ${ }^{238} \mathrm{U}$ and ${ }^{239} \mathrm{Pu}$, and further recycled while the other radioactive fission products are separated, sorted out according to their half-lives and activity, and appropriately disposed of with minimum environmental disturbance. 
India exerts the closed cycle mode in lieu of its phased expansion of nuclear power generation, extending through the second and third stages. Indigenous technology for the reprocessing of the spent fuel, as well as the waste management program, have been developed by India through its own comprehensive research and development efforts, and the reprocessing plants were set up and are in operation, thereby attaining self-reliance in this domain.

India's second stage of nuclear power generation envisages the use of ${ }^{239} \mathrm{Pu}$ obtained from the first stage reactor operation, as the fuel core in Fast Breeder Reactors (FBR). The characteristic features of the FBR are: ${ }^{239} \mathrm{Pu}$ serves as the main fissile element in the FBR; a blanket of ${ }^{238} \mathrm{U}$ surrounding the fuel core will undergo nuclear transmutation to produce fresh ${ }^{239} \mathrm{Pu}$ as more and more ${ }^{239} \mathrm{Pu}$ is consumed during the operation; in addition, a blanket of ${ }^{232} \mathrm{Th}$ around the FBR core also undergoes neutron capture reactions which leads to the formation of ${ }^{233} \mathrm{U}$, which serves as a fuel for the nuclear reactors of the third stage of India's Nuclear Power Programme; and it is technically feasible to produce sustained energy output of 420 GWe from the FBR.

The setting up of ${ }^{239} \mathrm{Pu}$ fuelled Fast Breeder Reactor of 500 MWe power generation is in advanced stage of completion. Concurrently, it is proposed to use thorium-based fuel, along with a small feed of plutonium-based fuel in Advanced Heavy Water Reactors (AHWRs). The AHWRs are expected to shorten the period of reaching the stage of large-scale thorium utilization.

The third phase of India's Nuclear Power Generation program is to have breeder reactors using ${ }^{233} \mathrm{U}$ fuel. India's vast thorium deposits permit the design and operation of ${ }^{233} \mathrm{U}$ fueled breeder reactors. ${ }^{233} \mathrm{U}$ is obtained from the nuclear transmutation of ${ }^{232} \mathrm{Th}$ used as a blanket in the second phase ${ }^{239} \mathrm{Pu}$ fueled FBR. Besides, the ${ }^{233} \mathrm{U}$ fueled breeder reactors will have a ${ }^{232} \mathrm{Th}$ blanket around the ${ }^{233} \mathrm{U}$ reactor core which will generate more ${ }^{233} \mathrm{U}$ as the reactor goes operational, therefore resulting in the production of more and more ${ }^{233} \mathrm{U}$ fuel from the ${ }^{232} \mathrm{Th}$ blanket as more of the ${ }^{233} \mathrm{U}$ in the fuel core is consumed, helping to sustain the long-term power generation fuel requirement.

These ${ }^{233} \mathrm{U} /{ }^{232} \mathrm{Th}$ based breeder reactors are under development and would serve as the mainstay of the final thorium utilization stage of the Indian nuclear program. The currently known Indian thorium reserves amount to 358,000 GWe-yr of electrical energy and can easily meet the energy requirements during the next century and beyond [24].

The three-stage nuclear program is supported by the AHWRs, as it is expected to shorten the period of reaching the stage of large-scale thorium utilization. AHWR300-LEU is a 300 MWe, 
vertical, pressure-tube type, boiling light water-cooled, and heavy water-moderated reactor. The reactor incorporates a number of passive safety features and is associated with a fuel cycle having reduced environmental impact. The schematic of the main systems is shown in Figure 1 [25].

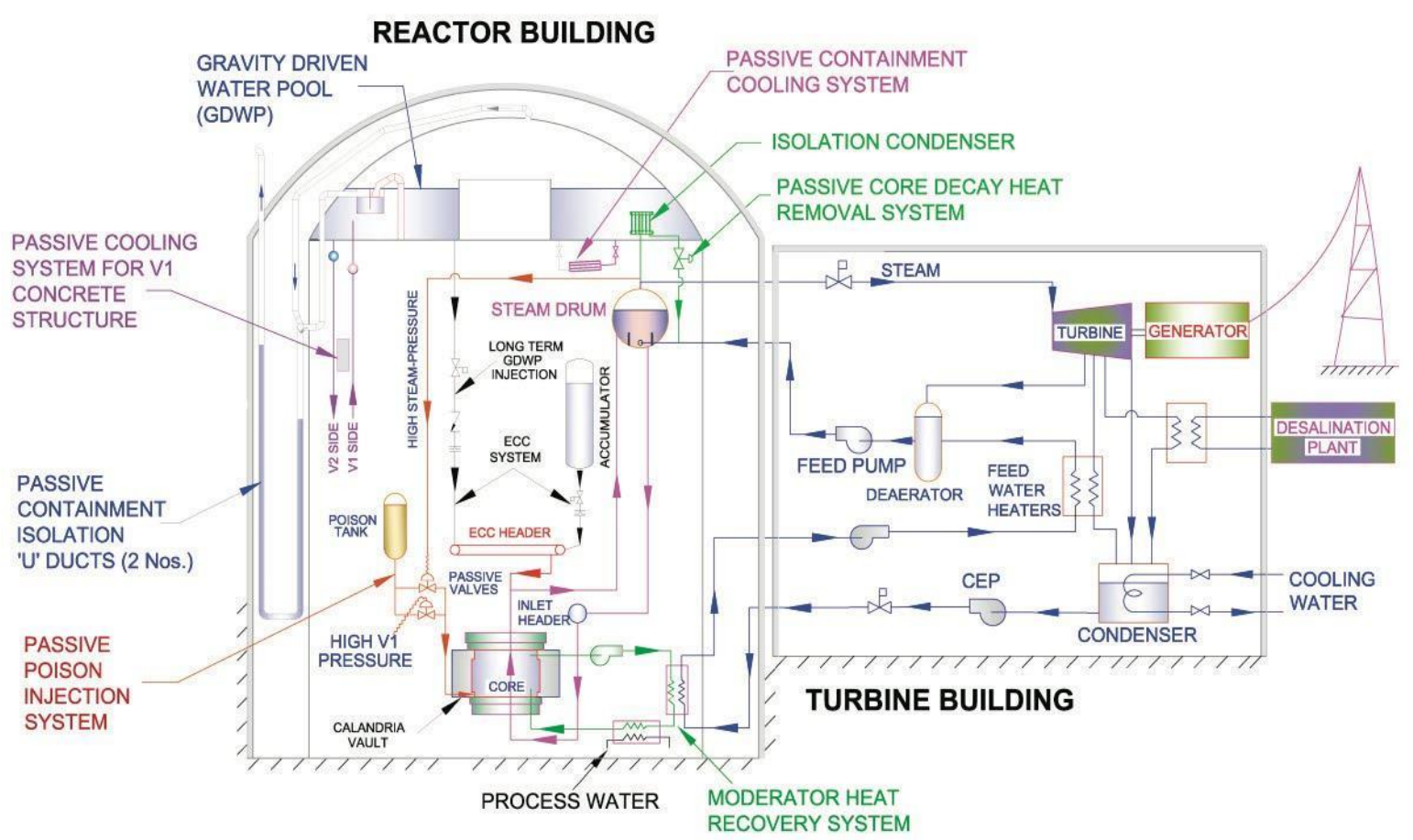

Figure 1: Schematic of AHWR 300-LEU main systems. Source: [25].

The AHWR300-LEU fuel cluster (Figure 2) contains:

- 54 fuel pins arranged in three concentric circles surrounding a central displacer assembly.

- The Zircaloy-2 clad fuel pins in the three circles, starting from the innermost, contain 18\%, $22 \%$ and $22.5 \%$ of $\mathrm{LEUO}_{2}$ (with $19.75 \%$ enriched uranium) respectively, and the balance $\mathrm{ThO}_{2}$. The average fissile content is $4.21 \%$.

- The moderator to be used here is Heavy Water $\left(\mathrm{D}_{2} \mathrm{O}\right)$. 


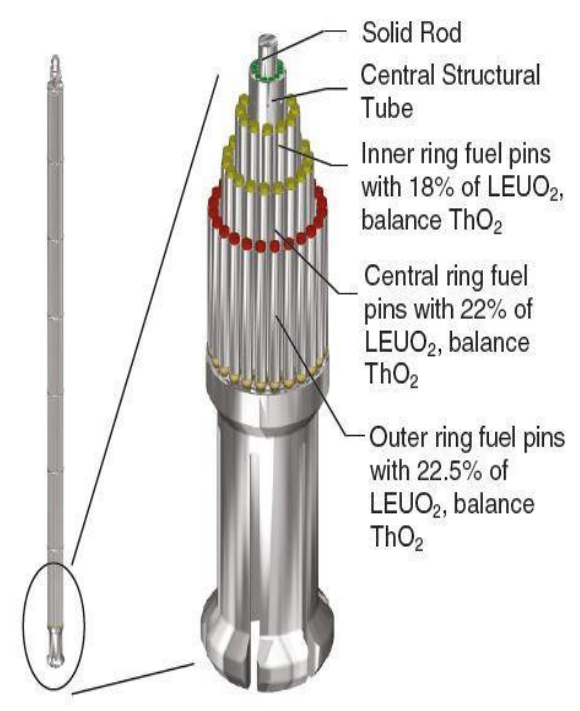

Figure 2: AHWR300-LEU fuel cluster.

Source: [25].

The AHWR300-LEU possesses several features that are likely to reduce its capital and operating costs. Some of them are listed below:

- Using heavy water at low pressure reduces potential for leakages.

- Recovery of heat generated in the moderator for feed water heating.

- Elimination of major components and equipment such as primary coolant pumps and drive motors, associated control and power supply equipment and corresponding saving of electrical power required to run these pumps.

- Shop-assembled coolant channels, with features to enable quick replacement of pressure tube alone, without affecting other installed channel components.

- Inherent advantages of using high pressure boiling water as coolant: elimination of steam generators, and use of high pressure steam.

- Production of $500 \mathrm{~m}^{3} /$ day of demineralized water in multi-effect desalination plant by using steam from LP Turbine (for plants located on the sea coast).

- Hundred years design life of the reactor [25]. 
In addition to better utilization of natural uranium resources, as compared to a modern LWR, AHWR300-LEU offers significant advantages in terms of proliferation resistance. As a result of its mixed fuel, the 300 MWe plant produces only $21 \%$ of the Plutonium as compared to a modern LWR. Further, the Plutonium from AHWR300-LEU spent fuel contains approximately 56\% fissile isotopes, while those from LWR spent fuel contains about $65 \%$ fissile isotopes. Also, fraction of

${ }^{238} \mathrm{Pu}$ in total plutonium, responsible for high heat generation, is around $10 \%$, as against a much lower fraction in modern LWRs, therefore making the Plutonium from AHWR300-LEU spent fuel much less attractive for proliferation. Figure 3 shows a comparison of the total plutonium at different burnups, against other reactors. An additional aspect of proliferation resistance is the appreciable quantities (approx. $200 \mathrm{ppm}$ ) of ${ }^{232} \mathrm{U}$ in the uranium from spent fuel of AHWR300LEU. The daughter products of ${ }^{232} \mathrm{U}$ emit high-energy gamma radiation. This makes it possible to re-use uranium in other reactors in a proliferation resistant manner. It may be further noted that due to its significant percentage of thoria, conventional approaches for dissolution are highly inefficient, thus making reprocessing more difficult $[26,27]$.

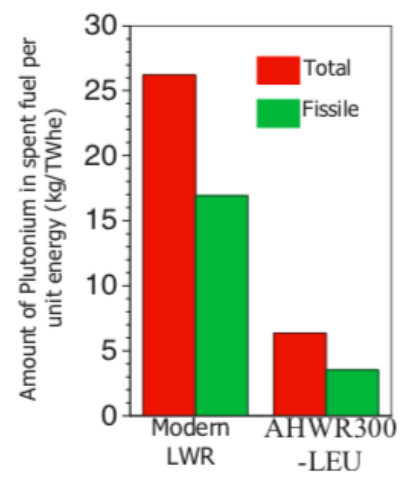

Figure 3: Reduced environmental burden due to reduced waste generation as compared to modern LWRs.

Source: [1].

The AHWR300-LEU fuel contains a significant fraction of thorium as a fertile host. Thorium being lower in the periodic table, the quantity of minor actinides is significantly reduced. As compared to the modern LWR, referred to in the previous section, for the same amount of energy produced, AHWR300-LEU results in 37\% less minor actinides (Figure 4). This will obviously lead 
to a reduced burden on waste disposal requirements, especially in view of the fact that a major portion of the future nuclear reactors may be deployed in countries with large population. Further, thorium oxide is eminently suitable for long-term storage because of the inert matrix. It is on account of this inert nature of the matrix, reprocessing of the AHWR300-LEU fuel poses relatively complex challenges. With this feature, even with a fuel cycle designed in a once through mode, the spent fuel can be kept stored at the plant site for prolonged durations, in interim storage facilities [1].

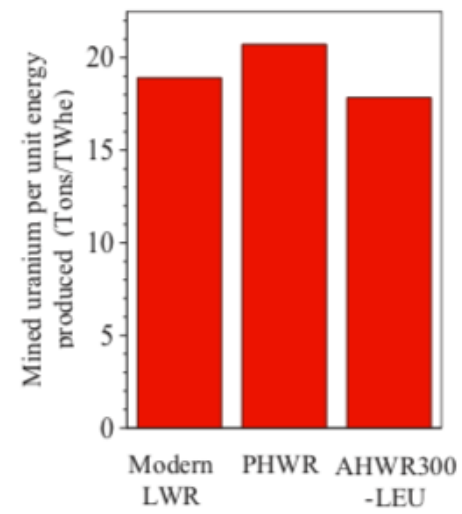

Figure 4: Production of actinides. Source: [1].

A Compact High Temperature Reactor (CHTR) is being designed to have many features, which make it inherently safe. In addition, many passive systems have been incorporated for reactor shutdown and reactor heat removal under normal and postulated accident conditions. The reactor possesses the following inherent safety features:

- A strong negative Doppler coefficient of the fuel for any operating condition results in reactor power reduction in case of fuel temperature rise, during any postulated accident scenario.

- High thermal inertia of the all-ceramic core and low core power density results in very slow temperature rise of the reactor core components, as well as fuel during a condition when all heat sinks are lost.

- A large margin between the normal operating temperature of the fuel (around $1100^{\circ} \mathrm{C}$ ) and the allowable limit of the TRISO (Tristructural Isotopic) coated particle fuel $\left(1600^{\circ} \mathrm{C}\right)$ to retain 
fission products and gases results in their negligible release during normal operating conditions. This also provides a healthy margin to take care of any unwanted global or local power excursions.

- A negative moderator temperature coefficient results in lowering of reactor power in case of increase in moderator temperature due to any postulated accident condition.

- Due to the use of lead-bismuth (Pb-Bi) eutectic alloy based coolant having a very high boiling point $\left(1670^{\circ} \mathrm{C}\right)$, there is a very large thermal margin to its boiling, the normal operating temperature being $1000^{\circ} \mathrm{C}$. This eliminates the possibility of heat exchange crisis and increases the reliability of heat removal from the core. The coolant operates at low pressure.

- The coolant, which is maintained in inert gas atmosphere, is itself chemically inert. Even in the eventuality of accidental contact with air or water, it does not react violently with explosions or fires; in case of a primary system leakage, the coolant solidifies and prevents further leakage.

- The thermal energy stored in the coolant, which is available for release in the event of a leak or accident, is small [1].

\section{DISCUSSION}

Considering the information on the AHWR300-LEU presented above, there are several attributes that can be related to the Green Chemistry principles:

Principle 1 - Waste prevention: as the AHWR300-LEU uses Thorium as a fertile host, the quantity of minor actinides is significantly reduced, and the thorium oxide produced as waste has an inert matrix, so is more suitable for long-term storage. It is important to recall here the convergence with the seventh principle of the radioactive waste management, as adopted by IAEA [28] in 1995, which states that the generation of radioactive waste shall be maintained in the lowest level achievable. This can be understood as less waste volume and mass, lower activity, shorter half-lives and reduced radiotoxicity of the radionuclides contained in the waste.

Principle 2 - Maximize atom economy: although the principles of Green Chemistry were conceived for the production of goods using chemical processes and expressed as the ratio of the product mass to the mass of reagents, it seems perfectly applicable to the generation of energy. 
Using the closed fuel cycle, the output of energy per unit mass of the primary fuel mined (kilograms of thorium or uranium), or raw material for the exploitation of the energy source, is much higher than any other fuel cycle, including renewables, fossil fuels and other nuclear fuel cycles.

Principles 3 and 4 - Design less hazardous chemical syntheses, and safer chemicals and products: the desirable characteristics of the discussed fuel cycle are intrinsically achieved by the design of the energy generation system, thus meeting the idea behind the principle of safety by design.

Principle 6 - Increase energy efficiency: this principle can be associated to the second principle, as pointed out earlier, in which the energy output per unit mass of mined and manufactured goods are much higher than the alternatives.

Principle 10 - Design chemicals and products to degrade after use: this is an intrinsic property of the waste that naturally decays the activity and reduces the associated danger, although the time necessary for some radionuclides present in the waste generated in the fuel cycle to become harmless may extend to very long periods.

Principle 12 - Minimize the potential for accidents: the many passive systems incorporated in the reactor prevent the accident conditions to occur, in case of forced shutdown and heat reduction, as well as the use of heavy water at low pressure, which reduces the potential for leakages.

\section{CONCLUSION (BRAZILIAN TRIAL)}

In the 1960s, Brazil was in research to choose which type of nuclear power reactor to be built, as well as which fuel to use. With great reserves of both uranium and thorium in the country (according to the 2018 NEA/IAEA report, Brazil has the second largest thorium reserve on the planet, after India [29]), it was up to the governing authorities to decide which system would be the most suitable.

The Thorium Group was established in 1965 in the city of Belo Horizonte, a team of nuclear engineers that aimed to make Brazil autonomous in the design and construction of this type of reactor. The group's task was similar to that of India's Nuclear Program. Researchers were sent for training in France, and the first Brazilian research facilities applied to power reactors were created. 
Several studies of heavy water reactor physics were performed in these laboratories, with heavy water supplied by the United States. However, around 1968, the leaders of the country's electric sector started to defend the choice of reactor with light water and enriched uranium, which was eventually accepted by the federal government. The Thorium Group broke up shortly after this decision [30].

Fifty years ago the idea of building a thorium-powered power reactor was set aside, and three PWR (pressurized water) reactors were built using light water and enriched uranium. The thorium reserves remained idle. At some point in the future, the price of uranium will increase due to its decreasing availability, which may cause the cost-benefit variable to tip in favor of thorium reactors; it is worth starting to think about this as soon as possible.

\section{REFERENCES}

[1] SINHA, R. K. Advanced nuclear reactor systems - an Indian perspective. Energy Procedia, v. 7, p. 34-50, 2011.

[2] EPA - Environmental Protection Agency. Green Chemistry, 2019. Available at : <https://www.epa.gov/greenchemistry>. Last accessed: 10 June 2020.

[3] AHT - Atomic Heritage Foundation. India nuclear program, 2018. Available at: <https://www.atomicheritage.org/history/indian-nuclear-program>. Last accessed: 10 June 2020.

[4] KANNAN, U. ; KRISHNANI, P. Energy from thorium - an Indian perspective. Sadhana, India, v. 38, n. 5, p. 817-837, 2013.

[5] WCED - World Commission on Environment and Development. Our Common Future (Brundtland Report). New York City : Oxford University Press, 1987.

[6] AGÊNCIA ESTADO. O Que É Desenvolvimento Sustentável. O Estado de São Paulo, 28 July 2004. Available at: <https://educacao.estadao.com.br/noticias/geral,o-que-e-desenvolvimentosustentavel,20040728p8329>. Last accessed : 10 June 2020.

[7] WEBBER, M. J. ; RIGBY, D. L. The golden age illusion: rethinking postwar capitalism. New York City : The Guilford Press, 1996. 
[8] UNESCO - United Nations Educational, Scientific, and Cultural Organization.

Intergovernmental Conference of Experts on the Scientific Basis for Rational Use and Conservation of the Resources of the Biosphere, 1968. Available at :

<https://files.eric.ed.gov/fulltext/ED047952.pdf>. Last accessed : 10 June 2020.

[9] MEADOWS, D. H. ; MEADOWS, D. L . ; RANDERS, J. ; W.W. BEHRENS III, J. The Limits to Growth. New York City : Universe, 1974.

[10] IUCN - International Union for Conservation of Nature and Natural Resources, UN Environment Programme, World Wildlife Fund., Food and Agriculture Organization of the UN, UNESCO. World Conservation Strategy: living resource conservation for sustainable development. Gland, Switzerland : IUCN, 1980.

[11] IAEA - International Atomic Energy Agency. Inventory of Radioactive Waste Disposals at Sea. Vienna : IAEA, 1999.

[12] UNSCEAR - United Nations Scientific Committee on the Effect of Atomic Radiation. Sources and effects of ionizing radiation. New York City: United Nations, 1993. Available at : <https://www.unscear.org/docs/publications/1993/UNSCEAR_1993_Report.pdf >. Last accessed: 10 June 2020.

[13] LINTHORST, J. A. An overview: origins and development of green chemistry. Found Chem, v. 12, n. 1, p. 55-68, 2010.

[14] LAGO, A. A. C. Estocolmo, Rio, Joanesburgo: o Brasil e a três conferências ambientais das Nações Unidas. Brasília: IRBr, 2007.

[15] FOLHA ONLINE. Saiba o que é a Rio +10. Folha de S.Paulo, 2002. Available at: <https://www1.folha.uol.com.br/folha/especial/2002/riomais10/o_que_e.shtml>. Last accessed: 10 June 2020.

[16] WSF - World Social Forum. About the World Social Forum, 2016. Available at : <https://fsm2016.org/en/sinformer/a-propos-du-forum-social-mondial>. Last accessed: 10 June 2020.

[17] UNITED NATIONS. 17 Goals to Transform Our World, 2019. Available at: <https://www.un.org/sustainabledevelopment/>. Last accessed: 10 June 2020.

[18] ANASTAS, P. T. ; WARNER, J. C. Green Chemistry: theory and practice. New York City : Oxford University Press, 1998. 
[19] WAI, C. M. Green separation techniques for nuclear waste management. Amer Chem Soc Symposium Series, v. 1046, p. 53-63, 2010.

[20] WAI, C. M. Emerging separation techniques: Supercritical fluid and ionic liquid extraction techniques for nuclear fuel reprocessing and radioactive waste treatment. In: K. L. NASH ; G. J. LUMETTA. Advanced Separation Techniques for Nuclear Fuel Reprocessing and Radioactive Waste Treatment. Cambridge : Woodhead Publishing, 2011.

[21] SMITH, T. ; THOMAS, J. Radioactive waste not wasted with new green chemistry technology. Am Nucl Soc J, v. 15, p. 32-35, 2008.

[22] LAHIRI, S. ; CHOUDHURY, D. ; SEN, K. Radio-green chemistry and nature resourced radiochemistry. J Radioanal Nucl Chem, v. 318, n.3, p. 1543-1558, 2018.

[23] SEN, K. A Journey from the Crossroads of Green Chemistry and Radiochemistry. Science and Culture, India, v. 81, n. 9-10, p. 243-247, Sep-Oct 2015.

[24] ANL - Argonne National Laboratory. India's Baseline Plan for Nuclear Energy Selfsufficiency, 2009. Available at :

<http://large.stanford.edu/courses/2014/ph241/parekh1/docs/67057.pdf>. Last accessed: 10 June 2020.

[25] BARC - Bhabha Atomic Research Centre. AHWR300-LEU: Advanced Heavy Water Reactor with LEU-Th MOX Fuel, 2009. Available at : <http://www.barc.gov.in/reactor/ahwr.pdf>. Last accessed: 10 June 2020.

[26] BNL - Brookhaven National Laboratory. The Indian Advanced Heavy Water Reactor (AHWR) and non-proliferation attributes, 2012. Available at: <https://www.bnl.gov/isd/documents/79014.pdf>. Last accessed: 10 June 2020.

[27] SINHA, R. K. The IAEA's contribution to the peaceful use of nuclear power. Nuclear Power Newsletter, v. 3, n. 2 Special Issue, 2006.

[28] IAEA - International Atomic Energy Agency. Fundamental Safety Principles: safety fundamentals. Vienna: IAEA, 2006.

[29] NEA/IAEA - Nuclear Energy Agency/ International Atomic Energy Agency. Uranium 2018: Resources, Production and Demand. Paris : OECD Publishing, 2019.

[30] CAMARGO, G. O Fogo dos Deuses. Rio de Janeiro: Contraponto, 2006. 